\title{
Т.А. Исаченко
}

Российская государственная библиотека, Москва

\section{«Александрия» Чудова монастыря под № 51/353, cep. XV в. Особенности перевода и языка}

Аннотащчия: Популярная средневековая повесть об Александре Великом стала для русских читателей основным источником сведений о македонском царе, покорившем Восток, дошедшем до края земли и заглянувшем в потусторонний мир. Перевод относят к группе древнерусских переводов, появившихся на Руси достаточно рано (XII в.). В пределах настоящей статьи рассматриваются эпизоды повествования, которые наглядно демонстрируют, с какими трудностями перевода сталкивались переводчики и переписчики текста на разных этапах его освоения: на этапе первоначального осмысления текста (XII в.); при вторичном его освоении (XV-XVI вв.); наконец, на этапе современного перевода. Перевод Ал. выполнен в кирилло-мефодиевских традициях. Основным филологическим показателем здесь является соответствие смысла и выражения, понятность и простота, тяга с этимологизации, использование иноязычных вкраплений для обозначения терминологически привившейся лексики.

Popular medieval tale about Alexander the Great were the main source of knowledge about the macedonian tscar' for Russians. The article is devoted to some problems of Slavonic translations of the tale.

Ключевые слова: трудности перевода, смысл и выражение, понятность и простота, этимологизация, иноязычные вкрапления, терминосистема

Образ Александра Великого исключительно важен для русской истории. Средневековая повесть о легендарном полководце стала для русских читателей, пожалуй, основным источником сведений о македонском царе Александре, покорившем Восток, дошедшем до края земли и заглянувшем в потусторонний мир. Цель этого похода - подчинение себе могущественного Вавилона и окрестных земель, народы которых, по мнению, высказанного от имени Александра славянским переводчиком, столь нечестивы, что, в случае завоевания ими Святой земли, они осквернят ее святыни. Эта тема стала доминантой произведения. В отдельных списках памятника называется еще одна цель, стоявшая перед Александром - желание обрести бессмертие. Рассказ о победах Александра содержится в форме пророчеств в библейской книге пророка Даниила (VIII, 20-21), а в «Александрию», в свою очередь, включен сюжет о гробницах трех отроков, плененных когда-то Навуходоносором и погребенных близ Вавилона, в который вошел Александр. Таким замысловатым образом сюжет перекликается с книгой пророка Даниила. На русской почве сюжет развивается так, что Александр является покоренным народам провозвестником будущего христианства, а идея бессмертия, которого добивается он, постепенно соединяется с идеей бессмертия души. Из Поучений Кирилла Александрийского известно, что три отрока, о которых повествует книга пророка Даниила, не отступили от веры отцов и встретили мученическую смерть, казненные мечом царя Аттика. Сокрытые до пришествия Христа, они после Его Распятия, были воскрешены в числе первых 500 праведников. Так, 
через заимствование сюжета, идея бессмертия соединилась в «Александрии»с идеей воскресения.

Современные исследователи, вслед за А.И. Соболевским, относят «Александрию» (далее: Ал. - Т.И.) к группе древнерусских переводов. Перевод Ал. появился на Руси достаточно рано (XII в.), причем в полемике с В.М. Истриным акад. А.И. Соболевский даже привел аргументы в пользу того, что славянский текст (так называемой, Сербской Ал.) разъясняет некоторые места сохранившихся греческих списков и, следовательно, влияние греческого текста на славянский следует рассматривать с учетом предшествующего обратного влияния славянского на греческий [Соболевский, 1905, с. 140-145].

Текст Ал., включенный в Летописец Еллинский и Римский, позже вошел в Лицевой летописный свод (ЛЛС) как памятник хронографии. О.В.Творогов уточнил А.А. Шахматова и В.М. Истрина относительно времени появления 2-ой редакции ЕЛ - до 1435 г. и доказал использование в ЛЛС текста так называемого русского хронографа редакции 1512 г. [Творогов, 1975; 1989, с. 18-20]. Таким образом, в 1568-1576 гг. хронографическая Ал. была включена в состав второго

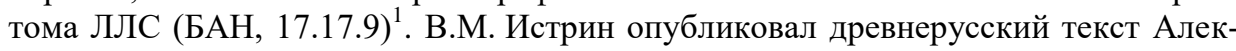
сандрии по четырем славянским спискам, в том числе списку Чудова монастыря № 51/353, сер.XV в., который исследовался в нашей работе [Истрин, 1893].

$$
* * *
$$

Перевод хронографической Александрии примыкает к группе так называемых «энциклопедических» переводов ${ }^{2}$, созданных в стенах митрополичьего скриптория XVI в. Своей популярностью в читательской среде эти тексты опровергают тезис Я.С. Лурье о правлении вел. кн. Василия Ивановича III как о «времени жесткой унификации русской культуры» [Лурье, 1960, с. 144-145]. Движение истории во всех рассматриваемых текстах осуществляется по одному и тому же кругу - из некоего мирового центра через Вавилон и Персию, державу Александра Македонского, Египет, Римскую империю и Византию на Русь.

В связи с новой волной интереса к Летописному Своду, вызванной подготовкой его современного факсимильного издания [Александрия, 2008], актуальность приобретает вопрос комментированного перевода Александрии, который в указанной (хронографической редакции) ранее не был осуществлен. Проблема такого перевода, в свою очередь, связана с обсуждением проблем переводческой практики и выработанных ранее критериев, анализом близкого круга текстов, историко-культурного контекста эпохи.

В пределах настоящей статьи рассматривается несколько эпизодов повествования, которые наглядно демонстрируют, как на разных этапах освоения текста переводчики сталкивались с определенными трудностями перевода: на этапе первоначального осмысления текста (согласно Истрину-Соболевскому, это происходило в XII в.); при вторичном его освоении (процесс включения текста в состав русского Хронографа и, далее, в состав ЛЛС; XV-XVI вв.); наконец, на этапе со-

\footnotetext{
${ }^{1}$ Александрия 2-й редакции, по В.М. Истрину, легла в основание текста второго тома ЛЛС, так называемого, Хронографического сборника БАН, лл. 587-797об. Том подготовлен к изданию [Александрия, 2008].

${ }^{2}$ K энциклопедическим рассматриваемые труды XVI в. отнесены нами, исходя из значения греч. enclyclios, 'круговой, совокупный, систематический“. Эпоха XVI в. характеризуется появлением энциклопедический сводов: Сводная Кормчая -свод важнейших церковных правил и гражданских законов, Лицевой летописный свод - самый значительный иллюстрированный хронограф средневековой Руси, Степенная книга царского родословия - важнейший идеологический памятник эпохи и Великие Четии Минеи - крупнейший нравоучительный четий свод этого времени.
} 
временного перевода в связи с составлением комментариев к готовящемуся факсимильному переизданию ЛЛС.

I этап. Примеры слов и выражений, вызвавших затруднения у древнерусских переводчиков в XII в.

О философских грамотах. Буквы, под которыми Александр скрыл в инициалах известие об основании им города, названы философскими грамотами очевидно, в том смысле, что они представляют некоторую загадку. В славянском переводе буквы переданы как А.В.Г.Д.Е., что не разъясняет загадки. Между тем, греческие буквы (грамоты) $\alpha, \beta, \gamma, \delta, \varepsilon$ означают: $\alpha$ - Александр, $\beta$ $\beta \alpha \sigma \imath \lambda \varepsilon \Uparrow \varphi$ (царь), $\gamma-\gamma \square$ оо $\varphi$ (род), $\delta-\Delta \mathrm{l} \circledast \varphi$ (бога), $\varepsilon-\square \kappa \tau \imath \sigma \varepsilon \pi \circledR \lambda \imath \nu$ (построил город). Лат. Alexander rex genus Jovis fecisset.

Подарки царя Дария с неверно переведенными греч. $\sigma \phi \alpha \square \rho \alpha v$, мяч и греч. $\sigma \kappa \diamond \tau о \varphi$, ллеть, которые во 2-ой редакции Александрии приобрели формы $\left(\sum \|\right.$ и | ( $\mid \sum \square$ С $\diamond:$ «меч дарю тебе, чтобы ты учился, а кочергу, чтобы играл с ровнями, не прельщая юных разбойников и не увлекал за собой, и не смущал города, как старый разбойник».

«Александр же, поим воя, и пойде от Треполя. И сретоша и Дарьевы послы, носяще к нему грамоту, и кочергу, и меч, и кръстичю с златом. И приим Александр грамоту Дарья, царя прьскаго, и, разгнув, написано сице послание: «Дарий, царь царем и богом сродник, и сияя солнцем. Аз сам бог Дарий - Александру, моему рабу, велю тако и заповедаю $\tau \diamond \diamond \pi(\lambda \circ \mathrm{o} ;$ или по млечному пути, по следам созвездии) възвратитися к родителем своимъ, мне же работая. И лежи у матери своей на лоне Алумпиаде. Тобе бо и еще подобает учитися съсати матерь. И щадя уность твою, и сего ти деля прислах мечь, и кочергу, и керстииу злата, да изберемши в том еже хощеши: мечь възвещаю ти, яко и еще подобает ти учитися, и кочергу, иже с ровнями своими играеши, а не аки старо тело нося, прельщаеши уныя и по собе водиши, аки старей разбойником, смущая грады» (л. 638об.).

О звездных колах, которые из созвездий (греч. к $\alpha \tau f-v / \mu \alpha \xi \alpha \nu)$ превратились в колеса с драгоченными камнями, освещавшими дорогу своим блеском

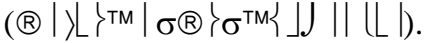

«О Афетовых внуцехи. И оттуды же, приим многи вожа, знающая пути индийския земля, въсхотех внити в западную страну пустыня въслед звездных кол. Тоземцы же глаголаху Александру, яко в странах тех дивии человецы суть и звирие злии и дивны. Александр же хотяше видети страну ту и человеки ты. Вождеве же глаголааху: “Владыко Александре царю! Не тъй есть путь Индейскиа земля”».

На II этапе (XV-XVI вв.), в процессе вторичного освоения текста, затруднения вызвали следующие эпизоды повествования:

а) переводчиком употреблено выражение замазати суньклитиком: Александр похвали Бога вышняго, повеле заковати врата железом и замазати суньклитиком, его же ни железо сечет, ни огнь жжет (т.е. повелел Александр заковать ворота железом и запечатать синклитом, который ни железо не точит, ни огнь не берет, л.695). Суньклитиком употреблено на месте ожидаемого суньклитомъ (где суньклитъ, вещество, не поддающееся воздействию огня и железа, подобно мрамору, из греч. ' $\sigma \vee \gamma \chi \cup \tau o v)$. Выражение впервые зафиксировано в «Откровении Мефодия Патарского» под 1377 г. ( 1096 г.), часто употребляется в летописях XVI в. Суньклитикъ вм. суньклитъ - ошибка вторичного освоения (греч.

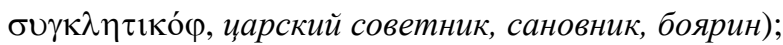

б) И видев же Александр ту болвана стояща, именем Ептаавея, не вельми велика суща, никакоже дивна, якоже есть писал Омир. Речь идет об изваянии кумира, именуемого Ептавей, которого увидел Александр. На месте греч. $\tau \prod \square \pi \tau \alpha \beta \circledR \varepsilon 10 v$ фигурирует вымышленное имя Ептаавей (ошиб. прочтение с вариантами написаний: Нептавей, Египет); 
в) к подобного рода ошибкам можно отнести врата адовы - предмет полемики Соболевского с Истриным.

III этап переводческой деятельности характеризуют трудности современного перевода, с которыми автор данной статьи столкнулся в процессе подготовки комментированного перевода Ал. в современном издании Летописного Свода.

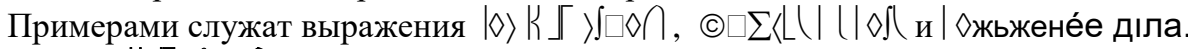

$. \diamond\rangle \sqsubseteq\rangle \int \square \diamond \bigcap$. Перевод выражения связан с попыткой толкования астрологических знаков, изображенных на скрижалях царя Нектанава, увлекавшегося астрономией и некромантией. Ал. открывается словами, которые ставят ее содержание в общую связь с текстами русского хронографа: «По Дарьи же [царе] Арсумуянине царьствова Александр Макидоньскый лет 12» (т.е. «Александр Македонский царствовал двенадцать лет после ассирийского царя Дария арсумуянина»). За этим следует родословная и сведения о родителях, в связи с чем появляется образ царя Нектанава-египтянина: «Мудрецы египетские, писавшие о Нектанаве, свидетельствовали, что тот отказался от чести царской, предпочтя ей звание кудесника». «И прославился Нектанав во всей Македонии своими пророчествами и умением гадать по звездам и стал известен всем живущим в стране той своим волшебством. Также и царица Олимпиада, слышавшая о нем, пришла к нему ночью - Филипп, муж ее, ушел тогда на войну - и, узнав от него то, что она хотела..., сказала: “Ты ли тот египетский учитель, которого испытали все и нашли в словах его подтверждение? Также и я хочу испытать тебя, действенна ли твоя хитрость, тогда поверю тебе"».

Нектанав отвечает Олимпиаде: ««Многомятежно есть ремество мор, о царице. Суть часници стражеве, раздрешители знаменйемъ, податели съномъ ... рожденйю влъхвове ...И вложив р1ку за паз1ху свою и выя дщицю, еяже слово указати не можетъ: златомъ тканымъ и слономъ обложена, имеющи звездъ седмь и часъныи стражь, солнце и л1ну...».

Объяснение смысла магических знаков на дощечках египетского царя вызы-

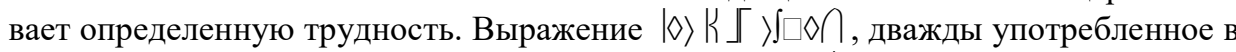
этом описании (один раз во множественном числе - аасници стражеве), не зафиксировано историческими словарями. В тексте проясняется смысл этого выражения, выражению $|\vartheta\rangle K \llbracket\rangle\lceil\square \diamond \bigcap$ дается парное слово w $\square \square$ роско| |, в значении 'небесные часы': «И вложив руку за пазуху свою и выя дщицю, еяже слово указати не может: златом тканым и слоном обложена, имеющи звезд седмь и часъный стражь, солнце и луну. Солнце же убо бяше хрустально, а луна адамантина, другый нарицаемый и Зеус въздушный, другый же Крон змеев, Афродити та же самъфирова, Арии же аматит, Ерьмиа же изъмарахтин, ороскоп же лугедин».

$\left.. \diamond\rangle K \int\left(|\diamond\rangle \mid \int K \int\right)\right\rangle \int \square \diamond \bigcap$ первой редакции Ал. видоизменен во второй редакции, где в данном месте читается $\mid(\square\rangle\langle\rrbracket\rangle \int \square \diamond \bigcap$, из чего следует, что др.-слав. |\rangle$\rangle \mid$ эквивалентно др.-слав. $|(\square\rangle|$. Согласно диалектным данным, выражение пояс на небе означает 'млечный путь' [Даль, 1882, т. 3, с. 376]; ср. у Иосифа Флавия: тм® $\left\{\left\{\diamond\right.\right.$ тм $\left.\left.\left.\sum\right\rangle \square\right]|| \square\right\rangle \mid\left\{\sum\left\langle\sum\right\rangle\{\rfloor \mid\right.$. Из чего следует допустить, на дощечках Нектанава присутствовало изображение млечного пути или зодиакального круга. Такие изображения действительно встречаются в русских средневековых рукописях.

Необъясненным при этом остается смысл, кроющийся в слове $\rangle \int \square \diamond \bigcap$. В интересующем нас контексте слово историческими словарями не прокомментировано. Диалектный материал позволяет восстановить у слова страж (в уменьшительной его форме стражик, сторожик) редкое значение 'стрелки весов': «Яко же стражик в перевесах, тако весь мир пред Тобою. Соломон» [Даль, 1882, т. 4, c. 334]. Отсюда ясно, что сказанное Нектанавом дословно означает: «Многотрудно знание мое, о, царица». Здесь и небесные пояса (вариант: стрелки небесных часов или весов), и предсказания, и приметы, и толкования снов, предвещающие рождение: «И, вложив руку за пазуху, он вынул дощечку, которую невозможно 
описать словами: была она выткана золотом и выложена слоновой костью, по которой были рассыпаны семь звезд и пояса созвездий, солнце и луна...».

$\wp \square \sum\left\langle\left\lfloor\left(|| \mid \diamond \int(\right.\right.\right.$. Выражение связано с представлениями о сооружении градостроительных укреплений: «... и прийде близ врат града Вавилона. Сущии же ту стражие, видевше его в таковом образе, мняху яко бога суща. Пытаху же у него, кто еси. Рече им Александр: “Дарьеви царю представите мя, тому бо повем, кто есмь”. Вне же бе Дарий града на высокых местех, гребля копая и покрывая пръстью, акы уроды творя макидоны» (л. 667 об.).

Речь идет о градостроительных укреплениях, может быть, о земляных валах, которые воздвигались вокруг Вавилона: когда Александр приблизился к городским воротам, то стражники, видевшие его в образе Аммона, решили, что видят самого бога. Стали они спрашивать его, что он такой. И отвечал им Александр: «Представьте меня царю Дарию, тогда скажу, кто я такой». Дария тогда не было в городе, ибо был он на высотах, делая насыпи и земляные валы $\left(@ \square \sum\langle\square|(\mid \diamond \square)\right.$, преграждавшие путь наступавшим войскам македонцев.

3৩жьжене́е діл'l. Толкование загадочного др.-рус. зажь, употребленного переводчиком в слитном написании зажьжене́е, стало пыткой не только для современного переводчика, но и для переписчика XVI в.: сотворив поминовение в честь Дария, царь Александр разослал указ по городам Персии, призывая жителей провинций жить своим прежним укладом, сохраняя нравы, и отмечая свои торжества, как при Дарии: «Всякое же бранное оружие велю принести в учиненыя ми храмы оружныя. Боляри же да пребывают во своем чину. Язык же на язык да не прийдет, нъ токмо зажь жения деля (с варинатом: дІла), и се же до 20 муж. И аз часть прииму по закону вашему, якоже было при Дарии. Хощу же страну вашу поставити в обильи» (л. 687). Говоря современным языком, данный эпизод может быть истолкован следующим образом: «Вельможи Персии пусть остаются в своих привилегиях, - писал он, - селения между собой не воюют, но только при передаче наследования по жене и числом не более чем двадцать мужей».

Древнерусское зажь, наследник, наследство отмечено единичной фиксацией по списку Русской Правды XIV в. (без зажу, без наследников [Словарь, 1990, т. III, c. 301]), а значит зажьжене́е діла необходимо читать в раздельном написании зажь жене́е діла, переводя его на современный язык фразой «только по делам наследования, то, что будет взято за женой».

В заключение выявленных наблюдений могут быть сделаны выводы теоретического характера.

Перевод Ал. выполнен в кирилло-мефодиевских традициях. Основным филологическим показателем здесь является соответствие смысла и выражения, понятность и простота, тяга к этимологизации, использование иноязычных вкраплений для обозначения терминологически привившейся лексики.

Как можно видеть, переводчик стремится избегать нагромождения экзотических слов, ведет его путем поиска новых переводческих средств. Греческой кальке он предпочитает описательную модель перевода, которая этимологически объясняет встретившееся слово: иже на коне яздити начнет, на немже есть волуя глава (из греч. Вочк $\square \alpha \lambda \mathrm{ov}$ ); в других редакциях Ал. поясняется происхождение имени коня Волуя голова тем, что конь имел на бедре клеймо с головой быка: $u$ наречеть же ся тоть конь Волуя глава, понеже имеяше на стегне знамение образ, имущ волую главу.

В.М. Истрин в свое время писал по этому поводу: «Переводчик вообще старался передавать греческие слова на своем языке и лишь в различных названиях удерживал слова оригинала, не переводя их; немного слов, которые не подходили бы под категорию технических названий, но и то надо объяснять, как следствие непонимания греческого текста, что в переводе встречается не редко» [Истрин, 1893 , c. 82]. 
В тексте присутствует около 150 грецизмов, большая часть которых хорошо адаптирована переводчиком и употребляется, главным образом, терминологически: кидарь (греч. $\kappa \square \delta \alpha \rho \varphi$ ), ияарское украшение первосвященников, головное по-

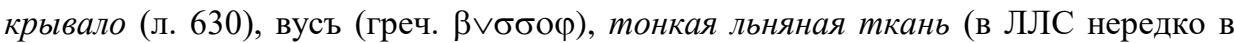

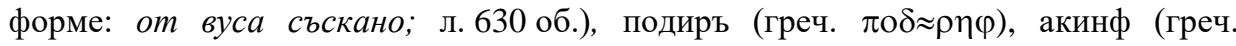
$\neg \leq \kappa \iota v \theta 0 \varphi)$, яхонт. Поэтому, когда в тексте встречаются малознакомые непереведенные выражения, такие как палица евелова (л. 587) - статусная принадлежность кудесника Нектанава, или панкратья и мантомаха для обозначения видов единоборств, то гипотетически можно предположить терминологичность этих понятий. И то и другое выражение в момент создания перевода могли быть хорошо известны на Руси (греч. $\square \leq \beta \delta$ о $\square \beta \varepsilon \lambda \mathrm{\imath} \approx v$, палища из черного эбенового дерева,

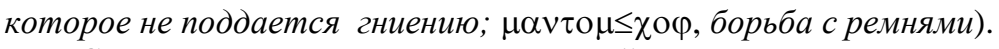

Следует указать ряд заимствований из латинского, немецкого, польского языков, которые в Ал. немногочисленны и отмечены в Словаре русского языка XI-XVII вв. ранними фиксациями:

1. яко шелковицы шиду, л. 702 (т.е. как тонкопряхи прядут шелковую нить), шида происходит от др.-верх.-нем. Sîde, лат. sēta, шелк);

2. дал ей за вено Рим, л. 625 (т.е. царь же Вуз взял ее за себя, и в качестве выкупа за невесту отдал Рим), вено происходит от лат. venum, приданое, выкуп за невесту;

3. акы с храбрыми некыми и с сведоки ратем, нъ акы с простыми и с страшливыми женами, л. 654 об. (т.е. я же готовлюсь к сражению с вами не как с храбрецами некими, прославившимися ратными подвигами, но как простыми и пугливыми бабами), сведоки происходит от др.-рус. съви́ди́ти, пол. swiadek, с XVI в.

Изучение переводных литератур и переводческих школ русского средневековья имеет солидную традицию. Опыт, накопленный палеославистикой в этой области, отличается вниманием к культурным связям России и Византии. Отмеченные наблюдения позволяют перейти к философскому обоснованию бытовавшей в XV-XVI веках переводческой практики, к описанию расхождений в использовании переводческих приемов. Комментированный перевод на современный русский язык хронографической Александрии (Александрии 2-й редакции по В.М. Истрину), легшей в основание текста второго тома ЛЛС и читающейся в рукописи Чудова монастыря № 51/345, послужил основой для наших наблюдений и соответствующих выводов.

\section{Литература}

Александрия Хронографическая второй редакции Псевдо-Каллисфена (Жизнеописание Александра Македонского // Лицевой летописный свод. Хронографический сборник. Научный аппарат к факсимильному изданию рукописи из фондов Отдела рукописей Библиотеки Российской Академии наук. (Лл. 587 - 797 об. Комментированный перевод Т.А. Исаченко). М., 2008.

Толковый словарь живаго великорусскаго языка Владимира Даля. СПб. М., 1880-1882. T. I-IV. 1893.

Истрин В.М. Александрия русских хронографов. Исследование и текст. М.,

Лурье Я.М. Идеологическая борьба в русской публицистике конца XV - начала XVI вв. М., 1960.

Словарь древнерусского языка XI-XIV вв. М., 1990. Т. III.

Соболевский А.И. К истории заимствованных слов в переводных повестях // Известия Отделения русского языка и литературы Имп. Академии наук. СПб., 1905. Т. Х. Кн. 2.

Творогов О.В. Древнерусские хронографы. Л., 1975. 
Творогов О.В. Летописец Еллинский и Римский // Словарь книжников и книжности Древней Руси. Вт. пол. XIV-XVI в. Л., 1989. Ч. 2. Л-Я. 